\title{
Article
}

\section{Care Planning and Review for Looked After Children: Fifteen Years of Slow Progress?}

Thomas, Nigel

Available at http://clok.uclan.ac.uk/2011/

Thomas, Nigel ORCID: 0000-0002-5310-9144 (2011) Care Planning and Review for Looked After Children: Fifteen Years of Slow Progress? The British Journal of Social Work, 41 (2). pp. 387-398. ISSN 0045-3102

It is advisable to refer to the publisher's version if you intend to cite from the work. http://dx.doi.org/10.1093/bjsw/bcr028

For more information about UCLan's research in this area go to http://www.uclan.ac.uk/researchgroups/ and search for < name of research Group >.

For information about Research generally at UCLan please go to http://www.uclan.ac.uk/research/

All outputs in CLoK are protected by Intellectual Property Rights law, including Copyright law. Copyright, IPR and Moral Rights for the works on this site are retained by the individual authors and/or other copyright owners. Terms and conditions for use of this material are defined in the policies page.

\section{CLoK}

Central Lancashire online Knowledge www.clok.uclan.ac.uk

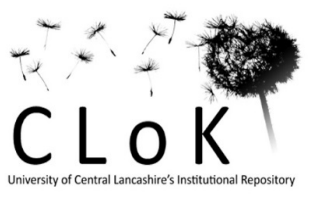


Critical commentary: Care planning and review for looked after children - fifteen years of slow progress?

\author{
Nigel Thomas \\ University of Central Lancashire
}

\begin{abstract}
This critical commentary reviews progress in research into planning and reviewing for children in care in England and Wales since the publication of two major studies in the late 1990s (roughly coinciding with the New Labour period). It briefly considers the changing context of law, regulation and guidance and the aims and objectives of the care planning and review system. It then reviews the limited research literature available, in relation to a series of key topics. Consideration is also given to guides for children and practitioners on the subject. The commentary concludes by suggesting that this is an area in which research has failed to keep pace with changes in policy and practice, and recommends a more systematic approach.
\end{abstract}

\title{
Introduction:
}

The aim of this critical commentary is to take stock of research into planning and reviewing for children in care, and point to some possible future areas of inquiry. The main focus is on the system in England and Wales, although reference is also made to policy and practice elsewhere. The commentary begins with a summary of the legal context (including regulatory changes during the period under review), followed by a brief overview of the literature and an explanation of the methods used to identify sources It then considers the state of research in relation to a series of particular themes and issues, and concludes with a brief review of guidance and some thoughts on future directions.

\section{The legal context}


The legal framework for child care planning and review in England and Wales derives mainly from the Children Act 1989 and reflects the underpinning philosophy of the Act, including the primacy of the child's welfare, the obligation to take account of the child's wishes and feelings, and the importance of continuing parental responsibility.

The provisions of the Children Act 1989 were based in part on earlier research into the shortcomings of the care system, in particular the tendency of children to 'drift' in the care system without clear plans being made for them (DHSS 1985). Continuing research into outcomes for looked after children also led to the development of the 'Looking After Children' system, which provided a range of materials to support the process of planning and review with a clear focus on identified outcomes (Parker et al., 1991; Jackson and Kilroe, 1996). This approach has been exported to other countries such as Canada (Kufeldt et al., 2003), while in England and Wales the tools have become part of the Integrated Children's System.

The main regulatory framework is contained in the Arrangements for Placement of Children Regulations 1991 and the Review of Children's Cases Regulations 1991. The key principles expressed in the regulations are: that every child who is looked after (whether in the care of the local authority or accommodated by them) should have a care plan; that this plan should be based on an assessment of their needs and on consultation with the child, their family and others whose wishes and feelings are relevant; and that the plan should include arrangements for a suitable placement and for meeting the child's present and developmental needs, including education and health care. The regulations specify the intervals at which cases are to be reviewed and how this should be done, with requirements for consultation and participation, implementation of decisions, monitoring and recording.

Amendments have subsequently been made to the original regulations. Research into poor outcomes for care leavers prompted the Children (Leaving Care) Act 2000, following which specific planning and review arrangements were introduced for young people as they approach the point of leaving care. Following the Adoption and Children Act 2002, the Review of Children's Cases (Amendment) (England) Regulations 2004 and the Review of Children's Cases (Amendment) (Wales) Regulations 2004 provided for the appointment of Independent Reviewing Officers. Following the Children and Young Persons Act 2008, the regulations were consolidated; the Care Planning, Placement and Case Review (England) 
Regulations 2010 come into force on 1 April 2011, together with new statutory guidance on care planning, placement and case review (HM Government, 2010) and an IRO Handbook which provides statutory guidance for independent reviewing officers (DCSF, 2010). Equivalent regulations and guidance for Wales have not yet appeared.

\section{Overview and methods}

The starting points for this commentary are two studies from the mid 1990s that, perhaps surprisingly, remain the only substantial examples of research into planning and review for looked after children., One was a general study of the operation of the care planning and review system (Grimshaw and Sinclair, 1997; Sinclair and Grimshaw, 1997). The other was an inquiry into children's participation in planning and reviewing, and in decision-making in care more generally (Thomas and O'Kane, 1998a; Thomas and O'Kane, 1999).

In order to identify more recent work, the following principal methods were used:

1. An electronic search using ChildData for all publications since 1990-2010 (Government reports and practice guides as well as research publications), using the keyword 'plans and reviews'.

2. A manual search through the following peer-reviewed journals for the period 1998-2010: Adoption \& Fostering, Child \& Family Social Work, British Journal of Social Work, Journal of Social Work and Journal of Social Welfare and Family Law. This looked for any research which focused wholly or partly on care planning and reviewing.

3. These two searches was supplemented with additional sources identified in a review by Sinclair (2006) for the Northern Ireland Commissioner for Children and Young People.

The ChildData search yielded 202 records initially, of which 22 were selected on the basis of abstracts. Only half a dozen of these were research-based and directly relevant. The journal search produced no articles focused centrally on processes of care planning and review for children and young people looked after, but a few with indirect relevance, for example on the LAC system, permanency planning, 'concurrent planning', delays in implementing plans, 
family group conferences, advocacy and children's participation. Overall the results of this search indicated a general neglect of the topic over the past decade or more. ${ }^{1}$

\section{Review of research}

The discussion that follows is focused on the following themes:

- objectives of planning and reviewing;

- the relationship with care planning in the courts;

- monitoring of planning and reviewing;

- participation of children and young people;

- $\quad$ perspectives of children and young people;

- perspectives of adults (both parents and professionals);

- new approaches to planning and reviewing.

These are issues on which the research literature has something to say. Other issues that have arisen in policy and practice, such as the role and impact of independent reviewing officers, are not well reflected in the literature.

\section{Objectives of care planning and review}

The primary aim of the planning and review system is to safeguard and promote children's welfare. Secondary objectives include promoting stability and permanence, enabling appropriate contact between family members, and ensuring a transparent process of decisionmaking to which all parties, including children themselves, have effective access. These and other secondary objectives clearly overlap, but do not necessarily always cohere perfectly.

The study by Grimshaw and Sinclair (1997) remains the only comprehensive examination of planning and reviewing under the Children Act 1989. The authors evaluated the operation of the Children Act's 'regulatory strategy' through a national survey and a detailed study in

\footnotetext{
${ }^{1}$ A similar search of the US journal Child Welfare for the same period yielded broadly similar results, with articles on family group decision making and on approaches to permanency planning, but nothing directly on planning and review for children in care.
} 
three local authorities (using case record analysis, review observations, individual and group interviews with children, interviews with parents and interviews with social workers and review chairs). The report encompasses: the legal and regulatory framework; its translation into local procedures and practices; processes of inquiry, consultation and assessment; the organisation of the review meeting; the participation of children and their parents; arrangements for chairing; the comprehensiveness and specificity of plans; continuity and effectiveness. It concludes with a series of detailed proposals for improving the regulatory framework. Grimshaw and Sinclair helpfully distinguish between planning ('a developing sequence in which the objectives of the plan and the current needs of the child are reconsidered on the basis of changing circumstances and fresh experiences', p.246) and review ('a process of considering the whole care plan, concluded by a final child-centred meeting and the completion of all the pertaining records', p.250).

Thomas and O'Kane (1999) looked specifically at children's participation in planning, review and other decision-making processes, using a combination of (i) data collected from social workers and file records on 223 children aged 8-12 looked after by five local authorities in Wales and one in England and (ii) an in-depth study of 47 of those children through multiple interviews and focus groups. They found that about half of children attended their meetings, but that levels of participation and degrees of engagement were highly variable and dependent on a range of contextual factors, particularly the age of the child, the context of decision-making and the attitudes of adults involved.

There is a substantial body of work that looks at planning mainly in a context of asking how to achieve the objective of permanence. Notable here is the work of Schofield and colleagues (Schofield, 2005; Schofield and Ward, 2008), who take a developmental approach to planning, and to children's involvement, based on attachment theory.

\section{The relationship with care planning in the courts}

At the same time as the regulatory framework for care planning and review by local authorities has developed, the courts have increasingly taken a more active role in the formulation and monitoring of plans for children on care orders, together with an expanded 
role for children's guardians, who are now employed by a central agency (CAFCASS and CAFCASS Cymru). The relationships between local authority care planning and review, the expectations of courts for oversight, and a range of adoption and fostering and other placement panels, make for a situation of considerable complexity, as Schofield and Ward (2008) note. Permanency planning meetings may be interposed between care planning, placement planning and periodic reviews.

Many authorities now also use models of 'concurrent' planning or 'twin track' planning, adding another layer of complexity. A study of the first UK pilot of concurrent planning by Wigfall, Monck and Reynolds (2006) concluded that a good deal of work will be needed to embed the model in practice, but that it has potential to offer a more effective route to permanence for some children.

Harwin (2003) looked directly at the role of the courts in planning, in a study that followed 100 children on care orders in order to identify what works for which children and in which circumstances. The research examined how effectively court care plans are implemented, and what factors appeared to contribute to successful outcome, concluding that care orders can only work effectively if there is sound knowledge of what contributes to placement stability and good welfare outcomes.

There is some evidence that other models of decision-making, such as the Scottish Children's Hearings system, can be more effective in enabling all parties, and in particular children and young people, to participate in planning (Murray and Hallett, 2000).

\section{Monitoring of care planning and reviews}

There have been virtually no studies of the monitoring and effectiveness of local authority planning and review since Grimshaw and Sinclair's original study. Roach and Sanders (2008) looked at obstacles to the implementation of plans for children in one local authority, by analysing the content of plans contained in 20 children's files (10 looked after ten and 10 on the child protection register). The focus was on delay in implementation of plans. Schofield and Ward (2008) report the existence of a range of systems for monitoring in the local authorities they studied. 
A key role in implementation now falls to Independent Reviewing Officers. To date there appears to have been no research into the work of IROs, despite the fact that the role has been developing informally since the early 1990s and on a statutory basis since 2004 .

\section{Participation of children and young people}

Cashmore (2002) argues that the reasons for involving children in decision-making are particularly cogent when they are in state care: the number of adults involved; the positive effect on children's self-esteem of having their views respected; the relationship between choice of placement and stability; and the value of preparation for independent decision-making. Thomas and O'Kane (1999) found that participation (in the sense of being invited and present at planning and review meetings) increased sharply at age 10 and steadily thereafter, till at age 12 more than $80 \%$ of children were invited to all or part of the meeting. Children were also more likely to be invited to routine reviews of progress than to planning meetings where major decisions were taken. Children whose parents were in conflict with the local authority were less likely to attend, even when invited. Children's ratings of their level of participation, in the sense of how much they contributed and what influence they had the outcome, were highly variable. Many children said that they felt listened to and supported in meetings, but few thought their views had much impact, especially if they did not agree with the social worker's opinion. Thomas and O'Kane (1998b) also found that there were often tensions between children's participation and adults' views of what was in their best interests, particularly around issues of returning home or having contact with family members.

Research in Norway (itself drawing on research and practice in England and Wales) suggests that discussion between social workers and children is unlikely to produce effective participation without the facility for children also to attend their reviews; and also that adult attitudes and communication skills are crucial in enabling children to take part and have an influence (Vis and Thomas, 2009; Vis, Holtan and Thomas, 2010; see also Vis, Holtan, Strandbu and Thomas, 2010). 
A small study by Children in Scotland (2006) found that both children and adults were interested and committed to the feelings and views of looked after children being heard and understood, but that official meetings and forms are 'imperfect vehicles... for ensuring the participation of children in decision-making' (p. 5). The most common problems described by children and adults were: 'inadequate preparation; a tension between a child-centred agenda and a professional-centred one; language or procedures that children find confusing, boring or off-putting; and, the lack of effective tools, skills and methods for use with young and/or less verbally-adept children' (p. 6). The report recommended more time for social workers to spend with children, more child-friendly meeting environments and procedures, separate forms for different age groups, and greater clarity in purposes and agendas.

\section{Perspectives of children and young people}

There is more evidence as to what children and young people think about their involvement in plans and reviews. A large survey of young people in care conducted by the Who Cares? Trust (Shaw, 1998) confirmed earlier research in that many children and young people complained of not feeling listened to. A more recent survey (Timms and Thoburn, 2006) focused on care planning and the courts, and found that a large majority said that they had not helped to write their care plan, and a smaller majority did not think that the social worker and/or the Court listened to them and respected their rights. The authors note: 'It is clear from the responses that not being listened to is a problem for some whilst in care and that this is exacerbated by lack of knowledge about the way in which young people can influence the decisions taken about them' (p. 13).

The more in-depth research of Grimshaw and Sinclair (1997) and Thomas and O'Kane (1998a) indeed showed that although children were often enthusiastic about being involved in decisions about their own lives, many were disenchanted with the the planning and review process and even felt alienated or marginalised. Similar findings have emerged from many smaller studies of children's views, for example Munro (2001). Leeson (2007) reflected back with a small group of young people at how feelings of helplessness, low self-esteem and poor confidence had followed from their experience of being excluded from key decisions about their own lives. These young people had experienced corporate parenting as impersonal and systems-orientated rather than child-centred. 
Morgan (2006) reports the views of 86 children and young people on decision-making and planning. Again, the picture is a mixed one. Nearly half said they felt included in plans, a higher proportion than in Timms and Thoburn's study, but common complaints about the process strongly echoed those of previous research. The report of the 'Blueprint' project (Voice for the Child in Care, 2004) also showed children's dissatisfaction with review meetings to be largely unchanged from research conducted a decade earlier.

\section{Perspectives of adults}

Although parents, carers and professionals may have very different perspectives on care planning and review, their views of the process are often congruent with those of children and young people. Thomas and O'Kane found that many social workers felt that review meetings were an unsatisfactory way of involving children in decisions: 'not enjoyable', 'a hollow exercise', 'a refined torture', 'a flawed tool', 'a paper exercise'. Although some parents and carers saw reviews as boring, repetitive and predictable, others welcomed them as a chance 'to thrash out issues' (Thomas, 2002: 161).

McCann, J. (2006) found a similarly mixed response among parents interviewed in her research for the NCB Care Planning project, some being very positive about the planning and review process while others were extremely negative. Grimshaw and Sinclair (1997) found that parental attendance at reviews had increased since the 1980s, and that parents were more likely to attend meetings for younger children or if the child was in a short-term placement; but make the point that attending a meeting does not in itself denote effective participation.

Voice for the Child in Care (2004) spoke to a senior manager who said

I would be horrified at the idea of all the people in my life - family, work, doctor, friends - being brought together in one room to talk about me.... There are too many people with some sort of investment in you at a review for you to be able to say what you really honestly feel. (52)

This echoes a young person quoted in the same report: 
We want to change the way reviews are done. I mean it's your home, you don't want a load of random strangers sitting in your front room. (51)

Thomas (2005) compared child care managers' perceptions of children's participation in decision in 1997 and 2004, finding signs of some change in 'culture', with more creative thinking about how to include children.

\section{New approaches}

Many organisations have looked for ways in which planning and review can be made more accessible and effective. A new approach was pioneered by the 'Children's Planning Initiative', an action research project by the Children's Society in North-West England, which aimed to create a unique planning framework centred on the individual young person and their wishes and needs, rather than fit each child into a pre-existing system (Adams and Welsby 1998).

There is evidence from much of the research reviewed here, particularly that based on children's views and on demonstration projects, that advocacy is of help to young people in taking part in decision-making. Thomas and O'Kane found that children valued support and informal advocacy, as did Leeson. As Dalrymple $(2001,2005)$ argues, while social workers and others have an advocacy role, sometimes formal advocacy is the only way to ensure that children's voices can be properly heard.

Boylan and Braye (2006) find much to welcome in the developing role of advocacy in the legal and policy framework for children's decision-making, but also express concerns about the nature and direction of such advocacy. Drawing on evidence from an empirical study of children's participation in statutory reviews and experience of complaints, they argue that the narrow focus of much advocacy provision and its professionalisation and 'marketisation' prevent it from being as valuable as it could be for children and young people.

\section{Guidance for children and practitioners}


The new statutory guidance will of course be a very important point of reference for practitioners in this area of work. In addition to this there are a number of guides produced by researchers and consultants which are intended to support and improve practice in planning and review. Some are aimed at practitioners: Thomas et al. (1999) is an integrated package of training and practice resources including tools for direct work; Kane (2007) provides a framework which can be adapted for use with any residential establishment; NCB (n.d.) is a website that offers guidance, training programmes, activities and presentations. Others are aimed directly at children and young people, some produced locally, others nationally. For example, Lanyon and Sinclair (2005a and 2005b) offer checklists and suggestions for children and young people of different ages on what to do before, during and after reviews. All the above guides are based on research to varying degrees, as well as on experience in practice and the feedback of children and young people.

\section{Conclusion}

As noted, there have been significant changes in the law, policy and practice of care planning and review since the last substantial research was conducted fifteen years ago. In particular the new leaving care provisions, the development of care planning in the courts, the expanded role of children's guardians, and above all the growth and formalisation of the IRO role, suggest that new research is seriously overdue. At the same time the questions raised in earlier research about the participation of different parties, especially children, are as urgent as ever. If nothing else, it would be useful to know if patterns of participation have changed as a result of the investment by many organisations, including government, in training, guidance and toolkits. Considering the time and resources that go into this area of practice, and its importance in light of the drive to improve stability and promote good outcomes, it would be useful to know how things are working and what, if anything, is making a difference.

\section{Acknowledgements}


This commentary is based in part on material gathered for a research review published by Community Care Inform (http://www.ccinform.co.uk/) and used here by kind permission. The author also wishes to thank Nicola Hilliard, NCB Librarian, for assistance with the Childdata search.

\section{References from search}

Boylan, J. and Braye, S. (2006) 'Paid, professionalised and proceduralised: can legal and policy frameworks for child advocacy give voice to children and young people?' Journal of Social Welfare and Family Law 28(3-4), 233-249.

Cashmore, J. (2002) 'Promoting the participation of children and young people in care', Child Abuse \& Neglect 26(8), 837-847.

Children in Scotland (2006) My Turn To Talk? The Participation Of Looked After And Accommodated Children in Decision-Making Concerning Their Care, Children in Scotland.

Dalrymple, J. (2001) 'Safeguarding young people through confidential advocacy services', Child \& Family Social Work 6(2), 149-160.

Dalrymple, J. (2005) 'Constructions of child and youth advocacy: emerging issues in advocacy practice', Children \& Society 19(1), 3-15.

Harwin, J. (2003) Making care orders work: a study of care plans and their implementation, London: The Stationery Office.

Kane, S. (2007) Care planning for children in residential care. London: National Children's Bureau, National Centre for Excellence in Residential Child Care.

Kufeldt, K., Simard, M. and Vachon, J. (2003) 'Improving outcomes for children in acre: giving youth a voice', Adoption \& Fostering 27(2), 8-19.

Lanyon, C. and Sinclair, R. (2005a) My turn to talk: a guide to help children in care aged 11 or younger have a say about how they are looked after. London: National Children's Bureau.

Lanyon, C. and Sinclair, R. (2005b) My turn to talk: a guide to help children in care aged 12 or older have a say about how they are looked after. London: National Children's Bureau.

Leeson, C. (2007) 'My life in care: experiences of non-participation in decision-making processes', Child \& Family Social Work 12(3), 268-277. 
McCann, J. (2006) Working with parents whose children are looked after, London: National Children's Bureau.

Morgan, R. (2006) Placements, decisions and reviews: a children's views report, Newcastle upon Tyne: Commission for Social Care Inspection.

Munro, E. (2001) 'Empowering looked after children', Child \& Family Social Work 6(2), 129-137.

Murray, C. and Hallett, C. (2000) 'Young people's participation in decisions affecting their welfare', Childhood 7(1), 11-25.

Roach, G. and Sanders, R. (2008) 'The best laid plans? Obstacles to the implementation of plans for children', Adoption \& Fostering 32(4), 31-41.

Schofield, G. (2005) 'The voice of the child in family placement decision-making: a developmental model', Adoption and Fostering 29(1), 29-44.

Shaw, C. (1998) Remember My Messages, London: Who Cares? Trust.

Sinclair, R. (2006) Child-centred care planning: a review of the literature, Belfast: Northern Ireland Commissioner for Children and Young People.

Thomas, N. and O'Kane, C. (1999) 'Children's participation in reviews and planning meetings when they are "looked after" in middle childhood', Child and Family Social Work 4(3), 221-30.

Timms, J. and Thoburn, J. (2006) 'Your shout! Looked after children's perspectives on the Children Act 1989', Journal of Social Welfare \& Family Law 28(2), 153-170.

Vis, S. and Thomas, N. (2009) ‘Beyond talking - children's participation in Norwegian child protection cases' ('Ikke bare snakk - barns deltakelse i Norske barnevernssaker'), European Journal of Social Work 12(2), 55-168.

Voice for the Child in Care (2004) Start with the Child, Stay with the Child: A Blueprint for a Child-Centred Approach to Children and Young People in Public Care, London: Voice for the Child in Care.

Wigfall, V., Monck, E. and Reynolds, J. (2006) 'Putting programme into practice: the introduction of concurrent planning into mainstream adoption and fostering services', British Journal of Social Work 36(1), 41-55.

\section{Other references}


Adams, R. and Welsby, J. (1998) 'The Children's Planning Initiative: researching decisionmaking for children', Systemic Practice and Action Research 11(3), 229-244.

DCSF (2010) IRO Handbook: Statutory guidance for independent reviewing officers and local authorities on their functions in relation to case management and review for looked after children, Nottingham: DCSF Publications.

DHSS (1985) Social Work Decisions in Child Care, London: HMSO.

Grimshaw, R. and Sinclair, R. (1997) Planning to Care: Regulation, procedure and practice under the Children Act 1989, London: National Children's Bureau.

HM Government (2010) The Children Act 1989 Guidance and Regulations Volume 2: Care Planning, Placement and Case Review, Nottingham: DCSF Publications.

Jackson, S. and Kilroe, S. (eds) (1996) Looking After Children: good parenting, good outcomes, London: HMSO.

NCB (n.d.) Care Planning for Looked After Children, available at http://www.ncb.org.uk/careplanning/index.html (accessed 28/04/2010).

Parker, R., Ward, H., Jackson, S., Aldgate, J. and Wedge, P. (1991) Looking After Children: assessing outcomes in child care, London: HMSO.

Sinclair, R. and Grimshaw, R. (1997) 'Partnership with parents in planning the care of their children', Children and Society 11(4), 231-241.

Thomas, N. (2002) Children, Family and the State: decision-making and child participation, Bristol: Policy Press.

Thomas, N. (2005) 'Has anything really changed? Managers' views of looked after children's participation in 1997 and 2004', Adoption \& Fostering 29(1), 67-77.

Thomas, N. and O'Kane, C. (1998a) Children and Decision Making: a summary report, Swansea: International Centre for Childhood Studies.

Thomas, N. and O'Kane, C. (1998b) 'When children's wishes and feelings clash with their "best interests" ،, International Journal of Children's Rights 6(2), 137-54.

Thomas, N., Phillipson, J., O'Kane, C. and Davies, E. (1999) Children and Decision Making: a training and resource pack, University of Wales Swansea, International Centre for Childhood Studies.

Vis, S.A., Holtan, A. and Thomas, N. (2010) 'Obstacles for child participation in care and protection cases - why Norwegian social workers find it difficult', Child Abuse Review, published online 17 Oct 2010 (DOI: 10.1002/car.1155). 
Vis, S.A., Holtan, A., Strandbu, A. and Thomas, N. (2010) 'Participation and health - a research review of child participation in planning and decision-making', Child \& Family Social Work, published online 13 Dec 2010 (DOI: 10.1111/j.1365-2206.2010.00743.x). 